\title{
Los procesos para la canonización de san Francisco Javier
}

\author{
The processes for the canonization \\ of St. Francis Xavier
}

Luis Javier FORTÚN PÉREZ DE CIRIZA

Archivero-Bibliotecario del Parlamento de Navarra

Prof. Asociado de Historia del Derecho - UPNA

https://orcid.org/oooo-0002-3552-5574

ljfortun@parlamentodenavarra.es

\begin{abstract}
The article analyzes the complicated itinerary that followed the various processes of canonization of the cause of St. Francis Xavier until the his canonization in 1622 . These processes, which took place in two stages, are notable for the a variety of geographical settings where they had place and by the number of witnesses who intervened. The first five trials (1556-1557) were carried out by order of King John III of Portugal. The second group is made up of nine pontifical processes (called «remisoriales»), held between 1610 and 1617 within the framework of the cause of canonization carried carried out by the Congregation of Rites by order of Pope Paul v.
\end{abstract}

Keywords: st. Francis Xavier, canonization process, John III of Portugal, Paulo V, Schurhammer, Society of Jesus.
Resumen: El artículo analiza el complicado itinerario que siguieron los diversos procesos de canonización de la causa de san Francisco Javier hasta la plasmación en su canonización de 1622. Estos procesos, que se desarrollaron en dos etapas, destacan por la gran variedad de escenarios geográficos donde tuvieron lugar y por la cantidad de testigos que intervinieron. Los cinco primeros procesos (1556-1557) fueron realizados por orden del rey Juan III de Portugal. El segundo grupo está formado por nueve procesos pontificios (llamados «renisoriales»), celebrados entre 1610 y 1617 en el marco de la causa de canonización llevada a cabo por la Congregación de los Ritos por orden del papa Paulo V.

Palabras clave: san Francisco Javier, proceso de canonización, Juan III de Portugal, Paulo v, Schurhammer, Compañía de Jesús.

En el año 2012 el Archivo Secreto Vaticano celebró el cuarto centenario de su fundación mediante una selecta exposición, en la que mostró solamente un centenar de piezas documentales, que trataron de demostrar la riqueza, diversidad o espectacularidad de sus fondos, a la vez que reflejaban hitos muy importantes de la historia de la Iglesia Católica o de la humanidad. Una de las piezas incluidas en el elenco expositivo fue la bula de canonización de san Francisco Javier, 
expedida por el papa Urbano VIII y datada el 6 de agosto de $1623^{1}$, primer día de su pontificado, que representaba el esfuerzo evangelizador llevado a cabo durante cinco siglos para hacer de una Iglesia europea una realidad verdaderamente Católica, es decir, universal. Una vez más la Iglesia Católica reconocía la relevancia que en su historia y su identidad, necesariamente unida al concepto de misión por voluntad de su Fundador, había tenido la elevación a los altares del santo navarro.

Esa relevancia se comprende bien si se tiene en cuenta que la canonización de san Francisco Javier, lejos de ser un hecho aislado o fruto de la decisión individual de un pontífice, exigió la participación de cuatro papas que rigieron la Iglesia Católica en la primera mitad del siglo XVII. Paulo V, a la vez que levantaba la fachada de la basílica Vaticana, llevo a cabo el proceso a partir de 1610 y lo proclamó beato (25 de octubre de 1619). Gregorio XV lo proclamó santo (12 de marzo de 1622). Urbano VIII expidió la citada bula de canonización. Inocencio X, que se hizo cargo del gobierno de la Iglesia Católica en 1644, era Giovanni Battista Pamphilii, uno de los tres auditores de la Rota Romana que habían gestionado el complejo proceso jurídico.

Su elaboración estuvo marcada por la reforma de la veneración de los santos y sus reliquias, que introdujo el Concilio de Trento en su sesión 25 (1563) y que se plasmó en la constitución apostólica Inmensa Aeterni Dei del papa Sixto V (22 de enero de 1588), que creó la Congregación de los Ritos y le atribuyó la regulación del culto y el estudio de las causas de los santos, que estuvo acompañada de la instrucción Causarum canonizationis. Estas normas marcaron una etapa de transición en la elaboración del procedimiento de canonización, que no quedó definitivamente fijado hasta que Urbano VIII promulgó la carta apostólica Caelestis Hierusalem cives (5 de julio de 1634), precedida por los decretos de Non cultu (1625 y 1631), que definieron la legislación básica de las causas de los santos hasta la reforma de las mismas por san Juan Pablo II en $1983^{2}$. En esta etapa de transición hay que situar la causa de san Francisco Javier y los procesos que para ella se elaboraron, entre los que hay que distinguir dos tipos diferentes, los ordinarios o diocesanos, iniciados por el respectivo obispo

1 Apostle of the Indies. Bull canonizing St. Francis Xavier, en Lux in arcana. The Vatican Secret Archives reveals itself, Roma, 2012, pp. 52-53.

2 Giovanni PAPA, Le cause di canonizzazione nel primo periodo della Congregazione dei Riti: (1588-1634), Urbaniana University Press, Roma, 2001, 392 p.; José Manuel MARCHAL MARTÍNEZ, Trento y la redefinición del Catolicismo. Los procesos de canonización, en Memoria honrosa de un Caballero. Estudios en el $V$ Centenario del Caballero de Gracia, Real Oratorio del Caballero de Gracia, Madrid, 2017, pp. 181-184. 
para poner en marcha el proceso, y los remisoriales o apostólicos, fruto de una decisión del Papa y de la Congregación de los Ritos, que marcaba el inicio de la fase romana ${ }^{3}$.

\section{TEMPRANO SOPORTE PORTUGUÉS PARA UNA DECLARACIÓN DE SANTIDAD}

La canonización de san Francisco Javier no contó con procesos ordinarios o diocesanos incoados por obispos, puesto que, cuando murió en 1552, no se habían producido ni el decreto de reforma del Concilio de Trento (1563) ni la legislación de Sixto V (1588). Fueron sustituidos por procesos incoados por una autoridad política, la monarquía portuguesa, pero que -no conviene olvidarlotenía importantes facultades religiosas a través de la concesión pontificia del $\mathrm{Pa}$ droado Portugues de Oriente (1460 y 1514), que le encomendaba la evangelización de los territorios que fuera incorporando a su imperio ultramarino.

Los pasos iniciales para lograr la canonización de san Francisco Javier los dio Juan III, el rey de Portugal (1521-1557) que le envió a evangelizar a la India y que sintió una profunda admiración hacia su labor, hasta el punto de aceptar no sólo las recomendaciones sino incluso los reproches que el misionero le hizo, de forma discreta pero enérgica, sobre el funcionamiento de los oficiales regios ${ }^{4}$.

En la primera flota que salió de Lisboa hacia la India una vez conocida oficialmente la noticia de la muerte del misionero, Juan III envió una real cédula, fechada en Lisboa el 28 de marzo de 1556 y dirigida al virrey o gobernador general Francisco Barreto, en la que, lleno de admiración hacia Javier, le ordenaba que recogiera en testimonios auténticos las cosas edificantes y obras sobrenaturales que Dios había obrado por medio de él:

Virrey amigo. Yo el Rey os saludo mucho.

La vida y trabajos que el Padre Maestro Francisco experimentó fue de tanto ejemplo y edificación que consideraría un gran servicio a nuestro Señor difundirlos para su gloria y alabanza. Y, para que esto se pueda hacer con la autoridad que

3 Una panorámica general de los procesos informativos y remisoriales para la canonización de San Francisco Javier la ofrece Georg SCHURHAMMER, Francisco favier. Su vida y su tiempo, III, Gobierno de Navarra, Pamplona, 1992, pp. 549-551.

4 Luis Javier FORTÚN PÉREZ DE CIRIZA, Realidad política e ideal religioso en la vida de San Francisco Favier, en Ignacio ARELLANo (coord.), Sol, Apóstol, Peregrino. San Francisco Favier en su Centenario, Gobierno de Navarra, Pamplona, 2005, pp. 80-91. 
se requiere, os encomiendo mucho que con la mayor diligencia posible hagáis extender en todas las partes de la India, donde haya personas dignas de fe que lo sepan, instrumentos auténticos de todas las cosas de edificación y obras sobrenaturales, que en vida de dicho Padre y después de ella nuestro Señor obró por medio de él; y que, una vez hecha, me la enviéis por dos vías, aprobada con toda la autoridad. $Y$ os lo agradeceré mucho.

Dada en Lisboa, a 28 de marzo de $1556^{5}$.

Conviene tener en cuenta que, en este escueto texto, Juan III: 1) parte de la convicción de considerar la difusión de la «vida y trabajos» de Javier como un servicio a la gloria de Dios; 2) exige relatarlos en «instrumentos auténticos», es decir, documentos redactados por notarios o escribanos dotados de fe pública, que era la máxima garantía de fiabilidad; 3) pide que los testigos sean «personas dignas de fe»; 4) quiere que la encuesta se haga «en todas las partes de la India», es decir en todo el ámbito de su imperio asiático; 5) el objeto es recoger «todas las cosas de edificación y obras sobrenaturales», tanto en vida de Javier como después de su muerte, que «nuestro Señor obró por medio de él», lo cual era tanto como confiar en la santidad de Javier, cuyas obras se consideraban sobrenaturales y actuaciones de Dios. De estos cinco rasgos se deduce que Juan III creía en la santidad de Javier, pero que, como no podía proclamarla abiertamente, porque esa facultad pertenecía a la Iglesia, ordenó recoger testimonios válidos de sus virtudes y hechos sobrenaturales con vistas a un futuro proceso de canonización.

El virrey Francisco Barreto, que también era denominado gobernador general, cumplió la orden en $\mathrm{Goa}^{6}$ y la transmitió expresamente a Basaín ${ }^{7}$, Cochín ${ }^{8}$, y Malaca ${ }^{9}$, plazas que cubrían, en sentido amplio, todos los dominios portugueses de las Indias Orientales. Los jesuitas se sumaron con peticiones o requerimientos en el mismo sentido en las tres últimas ciudades. Como era lógico, quedó fuera de este esfuerzo recopilador el Japón, porque el rey portugués no podía extender su autoridad fuera de sus posesiones ni promover actos jurisdiccionales en un imperio ajeno.

5 Monumenta Xaveriana ex autographis vel ex antiquioribus exempli collecta («Monumenta Historica Societatis Iesu», 16), II, Madrid, 1912, p. 174. Es traducción personal del original portugués. En adelante los Monumenta Xaveriana se citan por la sigla MX.

6 Proceso de Goa 1. Es el único que tiene dos versiones diferentes en portugués y en latín, que se citarán en adelante como Goa 1 P y Goa $1 \mathrm{~L}$.

7 Formalmente se han considerado dos procesos, aunque el segundo puede conceptuarse como un complemento del primero (Basaín 1 P y Basaín 1 L; Basaín 2 P y Basaín 2 L).

8 Proceso Cochín 1 P y Cochín 1 L.

9 Proceso Malaca $1 \mathrm{P}$ y Malaca $1 \mathrm{~L}$. 
El procedimiento de génesis y transmisión documental de estos cinco procesos fue el mismo. Un texto preambular invocaba la orden del rey o la provisión del virrey o gobernador general y determinaba el juez local y el escribano o notario encargado de realizar la averiguación o encuesta. Actuaron como jueces subdelegados los vicarios de las respectivas ciudades. Se incluía también el requerimiento del superior del respectivo colegio local de los jesuitas, que actuaba como procurador de la causa ${ }^{10}$. Cada una de las declaraciones de los testigos contaba con las firmas del juez, el notario y el propio testigo ${ }^{11}$, que garantizaban la autenticidad pedida por el rey. Su estructura se asemejaba bastante a los posteriores procesos ordinarios o diocesanos, que constaban de sesiones preliminares de constitución del tribunal, declaraciones de los testigos y sesiones conclusivas y de formalización de las actas ${ }^{12}$.

Los originales quedaron en la India, así como las copias pedidas por los jesuitas. Los textos editados son primeras o segundas copias notariales de los procesos, que, además del escribano, eran adveradas por uno o dos funcionarios más dotados de fe pública, para reforzar su autenticidad. A través de conductos o flotas diferentes, para garantizar que por lo menos una llegaba a su destino, se enviaron a Portugal dos ejemplares, como pidió el rey, o incluso tres, como se hizo desde Malaca. Su conservación en los archivos de la metrópoli fue problemática ${ }^{13}$. Además del texto originario en portugués, se conserva de cada proceso una versión en latín que, como se explicará más adelante, fue realizada en 1612 .

La flota de Lisboa que traía la orden real de hacer los procesos llegó a Goa a principios de septiembre ${ }^{14}$. El primer proceso de Goa se inició el 18 de noviembre de 1556. En la primera versión, hoy conservada en portugués y terminada el 9 de diciembre, se recogieron 31 declaraciones ${ }^{15}$. Ocho meses más tarde, en agosto de 1557, se añadieron seis testigos más, hasta alcanzar los 37 testigos, y se cambió

10 Salvo Basaín 2, que corrió a cargo del auditor general de la India.

11 La excepción es Basaín 1, en el que cada testimonio sólo va seguido de la firma del notario, sin que se añadan las del testigo y el juez.

12 José Manuel Marchal MarTíneZ, Trento y... procesos de canonización, p. 185-186.

13 Se encontraban en una caja en los Archivos Nacionales de Lisboa. Los cinco procesos fueron los únicos que se conservaron íntegros y pudieron ser editados, porque el resto de los documentos de la caja estaban convertidos en pequeños pedazos («vertantur in frustula») y no pudieron ser estudiados (MX, II, 1020-1021).

14 Malaca 1 P (MX, II, p. 414).

15 Goa 1 P. Hasta el 2 de diciembre declararon 25 testigos y el propio juez; el 9 de diciembre se añadieron cinco más. 
el orden, pero no el contenido, de cinco de ellos. Esta nueva versión, hoy perdida en portugués, se conserva en su versión latina de $1612^{16}$.

Cuando se contempla el elenco de testigos del proceso goano, destaca en primer lugar la ausencia de clero, tanto regular (franciscanos, dominicos), como secular (canónigos, párrocos). La sede episcopal estaba vacante y ejercía como vicario general un seglar, Ambrosio Ribeiro, que dirigió el proceso y lo cerró con su testimonio. Tampoco declararon quienes mejor conocían a Javier, los jesuitas de Goa. La ausencia de jesuitas como testigos fue un rasgo común en este primer grupo de procesos de 1556-1557, para evitar que sus testimonios fueran considerados carentes de veracidad o tachados de partidismo. Sí participaron laicos muy afines a la Compañía, como el funcionario Cosme Anes o Violante Ferrei$\mathrm{ra}^{17}$. Por lo mismo, quizás, tampoco declaró el gobernador o virrey, Francisco Barreto, a quien Javier había elogiado y recomendado ante el rey Juan III. Todos los testigos fueron portugueses, miembros de la élite que dirigía la colonia, y se pueden agrupar en cinco categorías: funcionarios, especialmente de la hacienda real (contador, veedor, factor, almojarife, escribano, médico) ${ }^{18}$; miembros de la pequeña nobleza radicada en la colonia (caballeros e hidalgos de la casa real) ${ }^{19}$; pilotos y patronos de naves ${ }^{20}$; vecinos de Goa, cabezas de familia respetables, algunos de ellos comerciantes enriquecidos ${ }^{21}$; y finalmente cinco mujeres relacionadas con los anteriores ${ }^{22}$. Todos ellos aportaron sus propias vivencias o referencias de otros testigos, que dejaron constancia del celo apostólico de Javier, sus virtudes, sus dones sobrenaturales (en especial el de profecía y el anuncio de hechos coetáneos pero separados en el espacio). También quedó acreditada la emoción que supuso la llegada a Goa de su cuerpo incorrupto, acogido por una multitud y la veneración que inmediatamente recibió al ser mostrado públicamente durante dos días.

16 Goa 1 L. Se cambió el orden de las declaraciones de los cinco testigos del 9 de diciembre de 1556 $\left(n^{\circ} 27\right.$ a 31), se añadieron tres testigos, que declararon el 3 de agosto de 1557 ante los mismos juez y notario, y otros tres que lo hicieron el 18 de agosto ante el mismo juez, pero no ante el mismo notario. El testimonio del juez, que en la primera versión ocupaba el lugar 26, antes de los testigos del 9 de diciembre de 1556, pasó a cerrar el texto en último lugar.

17 Cosme fue protector del Colegio de San Pablo y murió dentro de él. Violante era considerada por Javier como «madre» de la casa de Goa (Georg SCHURHAMMER, Francisco Favier, IV, Gobierno de Navarra, Pamplona, 1992, p. 129 y 725-726).

18 Goa $1 \mathrm{~L}$, testigos $\mathrm{n}^{\circ} 1,5,6,7,8,16,30$.

19 Goa $1 \mathrm{~L}$, testigos $\mathrm{n}^{\circ}$ 3, 4, 16, 20, 24, 25, 31, 32, 33, 35, 36.

20 Goa $1 \mathrm{~L}$, testigos $\mathrm{n} 1$ 10, 11, 12, 13.

21 Goa $1 \mathrm{~L}$, testigos $\mathrm{n}^{\circ} 2,17,23,26,27,28,29,34$.

22 Goa $1 \mathrm{~L}$, testigos $\mathrm{n}^{\circ} 14,15,18,19,20$, 
En los primeros días de diciembre partió desde Goa hacia Basaín la orden para celebrar un primer proceso, que duró un día, el 8 de diciembre de 1556. Javier apenas había estado una vez en Basaín para entrevistarse con el virrey, sin desplegar allí una especial actividad apostólica, pero en esta ciudad residían siete testigos que podían aportar datos de su actividad no sólo en la India, sino también en Malaca y las islas Molucas. Actuó como juez delegado el vicario de la ciudad, P. Simón Travasos, y como escribano el P. Francisco de Carvalho, beneficiado $^{23}$. Los jesuitas consideraron oportuno ampliar las informaciones con otros dos testigos, dando lugar a un segundo proceso de Basaín, que realizó el licenciado Enrique Jaques, auditor general de la India, con la colaboración del escribano Lope de Aguiar, que era uno de los dos testigos (6 de enero de 1557) ${ }^{24}$. Aunque formalmente son dos procesos distintos, los testigos y sus declaraciones pueden analizarse conjuntamente ${ }^{25}$. Los nueve declarantes son portugueses y entre ellos predominan los que pertenecían a la baja nobleza (cinco hidalgos de la casa real) ${ }^{26}$, seguidos por tres funcionarios locales (el factor de la hacienda real, el merino del término municipal y un escribano) ${ }^{27}$; sólo uno era franciscano y había sido mercader ${ }^{28}$. Interesaba más su proximidad al futuro santo. Tres le habían acompañado en su viaje desde Lisboa a la India y dos de ellos le consideraban su «padre espiritual» (Duarte de Miranda y Antonio de Sousa) ${ }^{29}$. Otros eran testigos de amplios periodos de su actividad. El franciscano Juan de Eiro había sido un mercader al que Javier convirtió de su azarosa vida en Santo Tomé y le acompañó en toda su estancia en Malaca y las Molucas (1545-1547), en donde fue testigo de alguna curación. Su testimonio es relevante porque da cuenta de sus propias flaquezas, castigadas por Javier, y del cumplimiento de la profecía del santo en el sentido de que acabaría siendo franciscano, que diez años después de formularse, cuando tuvo lugar el proceso, era realidad ${ }^{30}$. Juan de Artiaga, que le acompañó hasta 1545, acerca a los hechos sobrenaturales protagonizados por Javier en la Pesquería, distinguiendo entre los que vio y los que le contaron testigos pre-

23 Basaín 1 P. Contrariamente a otros procesos, las declaraciones de los testigos sólo van firmadas por el escribano P. Francisco de Carvalho.

24 Basaín 2 P. La primera declaración está firmada por testigo y escribano, mientras que la segunda sólo lleva la firma del testigo y a la vez escribano.

25 Georg SCHURHAMMER lo considera un único proceso (Francisco favier, III, p. 550).

26 Basaín $1 \mathrm{P}$, testigos $\mathrm{n}^{\circ}$ 1, 2, 5, 6, 7.

27 Basaín $1 \mathrm{P}$, testigo $\mathrm{n}^{\circ}$ 3; Basaín $2 \mathrm{P}$, testigos $\mathrm{n}^{\circ} 8,9$.

28 Basaín 1 P, testigo $\mathrm{n}^{\mathrm{o}} 4$.

29 Basaín 1 P, testigos $\mathrm{n}^{\circ} 1,2,3$.

30 Basaín $1 \mathrm{P}$, testigo $\mathrm{n}^{\circ} 4$. 
senciales $^{31}$. El don de visión también fue reforzado por el testimonio de varios testigos $^{32}$.

La elección de Cochín como sede de un proceso se comprende por las numerosas ocasiones en que el santo visitó la ciudad, en la que escribió abundantes cartas, destinadas a la flota que desde allí salía hacia Lisboa al finalizar cada año. Era además la fortaleza portuguesa más cercana a las costas de Travancor y la Pesquería. El primer proceso de Cochín tuvo lugar el día 8 de enero de 1557 y actuó como juez el vicario de la localidad, P. Pedro González, amigo de Javier, que le acogía en su casa durante sus estancias en la ciudad. Depusieron 13 testigos y todos ellos firmaron su correspondiente declaración junto con el vicario y el escribano P. Francisco Fernández. Más de la mitad de los testigos eran miembros de la pequeña nobleza portuguesa establecida en la ciudad (caballeros e hidalgos de la casa real) ${ }^{33}$ y sólo dos vecinos sin otro título ${ }^{34}$. Pero quizás los testimonios más interesantes proceden de los tres últimos en testificar: un acompañante en la primera estancia en Malaca $^{35}$, un parava cristiano de la Pesquería (Juan de la Cruz) ${ }^{36}$ y un sacerdote, Francisco Mansillas, que había sido su colaborador en la actividad misional de Pesquería y Travancor. El testimonio de Mansillas, que fue muy elogioso («su vida era más la de un santo y un ángel que la de una persona humana») ${ }^{37}$, tenía más valor por el hecho de que Mansillas había pertenecido a la Compañía de Jesús, aunque acabó siendo despedido de ella por Javier en 1548. Los tres dieron un testimonio unánime tanto del amor del santo por los paravas, que le llamaban «Padre santo» y a los que predicó y defendió frente a todos, como de su jovialidad y capacidad para trabar amistad con los pecadores para convertirlos. Son sin embargo muy cuidadosos al confesar que no fueron testigos de algunos milagros que conocían por fuentes cercanas. En cambio, una de las mayores aportaciones de tres caballeros fue dar testimonio como testigos presentes del milagro del anuncio de la victoria sobre los achines ${ }^{38}$.

Como la flota de Lisboa que trajo la orden real para hacer los procesos sobre Javier llegó a principios de septiembre de 1556, el gobernador general Francisco Barreto extendió rápidamente una provisión real para que se cumpliera en Mala-

\footnotetext{
31 Basaín $1 \mathrm{P}$, testigo $\mathrm{n}^{\circ} 4$.

32 Basaín 1 P, testigos $n^{\circ} 1,3,4,6,7$; Basaín 2 P, testigo $\mathrm{n}^{\circ} 9$.

33 Cochín $1 \mathrm{P}$, testigos $\mathrm{n}^{\circ} 1,2,4,6,7,9,10$.

34 Cochín $1 \mathrm{P}$, testigos $\mathrm{n}^{\circ} 3,8$.

35 Cochín $1 \mathrm{P}$, testigo $\mathrm{n}^{\circ} 12$.

36 Cochín $1 \mathrm{P}$, testigo $\mathrm{n}^{\circ} 11$.

37 Cochín $1 \mathrm{P}$, testigo $\mathrm{n}^{\circ} 13$.

38 Cochín $1 \mathrm{P}$, testigos $\mathrm{n}^{\circ} 2,4,7$.
} 
ca (10 septiembre 1556), con la esperanza de que una nave la llevara a Pulicat y pudiera entregarla en la nao real de Coromandel, que ese mismo mes partía en dirección a Malaca. Así debió de ser, porque dos meses después se inició el primer proceso de Malaca (24 noviembre 1556) a instancias del jesuita P. Baltasar Díaz. No lo presidió la autoridad eclesiástica de la ciudad, que era el vicario, sino la autoridad civil, personificada en Juan Pereira, capitán de la ciudad, que fue ayudado por el oidor Diego de Andrade. Sólo declararon dos testigos, porque los cuatro restantes lo hicieron en mayo de 1557, repartidos entre los días 2 y 19. Las seis declaraciones están firmadas por los dos encuestadores, el testigo y el escribano Diego Fernández. La extracción social de los seis testigos, todos portugueses, era similar a los procesos anteriores: cuatro pertenecían a la baja nobleza (hidalgos y caballeros de la casa real) ${ }^{39}$, un regidor miembro del ayuntamiento ${ }^{40}$ y un vecino de la ciudad ${ }^{41}$. El cuestionario contestado por los testigos, elaborado por el promotor jesuita, tiene una peculiaridad con respecto a los anteriores: trata de recoger ciertos hechos en relación con concretos atributos de la santidad cuidadosamente definidos: vida conforme a la ley evangélica, el don de profecía, existencia de gracias que Dios había dado a sus discípulos cuando los mandó a predicar y evangelizar, disposición a poner la vida en peligro de muerte por el celo de las almas... Aunque no fueron numerosos, los testigos de Malaca fueron importantes para acreditar estos extremos, en especial el don de profecía (el milagro de los achines) $)^{42}$ y una milagrosa curación, que conocieron directamente o a través de sus protagonistas ${ }^{43}$.

En conjunto, los cinco procesos realizados en Goa, Basaín, Cochín y Malaca en 1556-1557, fruto de la certera decisión de Juan III de Portugal, fueron muy importantes en la causa de canonización de san Francisco Javier. Una vez concluidos y enviados a Portugal, en 1559 se elaboró un resumen de todos ellos ${ }^{44}$. Hace un siglo Astrain consideró que valían poco, por estar hechos a la ligera, reducirse a seis o siete preguntas respondidas en términos generales y citando los mismos

39 Malaca $1 \mathrm{P}$, testigos $\mathrm{n}^{\mathrm{o}} 1,2,5,6$.

40 Malaca $1 \mathrm{P}$, testigo $\mathrm{n}^{\circ} 4$.

41 Malaca $1 \mathrm{P}$, testigo $\mathrm{n}^{\mathrm{o}} 3$.

42 Malaca $1 \mathrm{P}$, testigos $\mathrm{n}^{\circ}$ 3, 5. También la recuperación del batel volviendo del Japón (testigo $\mathrm{n}^{\circ} 1$ ).

43 Fue la curación de Antonio Fernández, hijo de Juan Fernández de Ilher y una javanesa, enfermo, endemoniado y sin habla, relatada por Antonio Mendes y el propio padre (Malaca $1 \mathrm{P}$, testigos $\left.\mathrm{n}^{\mathrm{o}} 3,6\right)$.

44 Fue publicado por Artur Basilio DE SÁ, Documentação para a bistória das Missões do Padroado Português do Oriente, II, Lisboa, 1954, pp. 183-232; Georg SCHURHAMmER, Francisco Favier, II, p. 752, 754. 
hechos ${ }^{45}$. Schurhammer desmintió esta descalificación, los definió como importantes, porque la mayoría de los testigos habían conocido a Javier y conservaban los recuerdos frescos ${ }^{46}$, y los usó con frecuencia en su monumental biografía de san Francisco Javier, por más que los sometiera a crítica. En realidad, estos seis procesos proporcionaron no sólo el conocimiento de hechos sobrenaturales muy importantes sobre san Francisco Javier, que quedaron definitivamente acreditados, sino también su entrega absoluta a la tarea evangelizadora y la existencia de un sensus fidelium favorable a quien era llamado en vida «Padre santo» y que se plasmó, tras la muerte, en la inmediata veneración de su cuerpo incorrupto que relatan. Además, tuvieron la virtualidad de sustituir a los procesos diocesanos y permitieron la incoación de los procesos pontificios o remisoriales, como se indica a continuación.

Las declaraciones recogidas en los cinco procesos de la India dejaban pendiente una cuestión muy importante. Todos los testigos que intervinieron en ellos eran portugueses, salvo uno de Cochín, el parava Juan de la Cruz. Evidenciaban la veneración de testigos y colaboradores cristianos hacia la persona y la obra de un misionero infatigable, pero sólo mostraban una cara de la evangelización y quedaba pendiente conocer las opiniones de los pueblos que habían recibido esa evangelización en la India, Indonesia y Japón y habían aceptado la fe católica.

\section{LOS PROCESOS REMISORIALES Y EL EMPUJE DEFINITIVO DE LOS INDIOS PARAVAS Y MALABARES A LA CANONIZACIÓN}

Una de las primeras peticiones de canonización de san Francisco Javier la dirigió al papa Gregorio XIII en 1583 un japonés, Otomo Yoshishige, daimyo de Bungo, que le había recibido en su feudo y que años más tarde se bautizó con el nombre de Francisco ${ }^{47}$. La causa era entonces inviable, porque, en el contexto del conjunto de la Compañía de Jesús, resultaba más lógico que la orden se esforzara

45 Antonio ASTRAIn, Historia de la Compañía de Jesús en su asistencia de España, I, 2ª ed., Madrid, 1912, p. XXI.

46 Georg SCHURHAMMER, Francisco favier, III, p. 549-550. No creo que puede otorgarse la categoría de «proceso» a las declaraciones que prestó Fausto Rodrígues, que conoció a Javier en Amboino en 1546, ante las autoridades eclesiásticas de Cebú (Filipinas) en 1608 y 1613. El rector del colegio de Cebú envió una copia al General de la Compañía (Archivum Romanum Societatis Iesu, ARSI, Philipp. 10, f. 278r-282v; pub. Georg SCHURHAMMER, en Gesammelte Studien, III, pp. 539544), pero no tuvo incidencia en la causa de canonización.

47 Georg SCHURHAMmer, Francisco favier, IV, pp. 322-328 y 834. 
en primer lugar en lograr la canonización de su fundador, san Ignacio de Loyola. Cuando este fue beatificado (27 de julio de 1609), quedó expedito el camino para plantear la de su discípulo. En 1610 se nombraron los tres jueces apostólicos encargados de examinar la causa, que fueron Francesco Sacrati, arzobispo titular de Damasco $^{48}$, Giovanni Battista Cocçino, decano de la Rota Romana, y Giovanni Battista Pamphiliii ${ }^{49}$, doctores en ambos derechos y auditores de la Rota. Se abrió un primer proceso de Roma (1610), calificado como general y que probablemente no fuera remisorial sino diocesano.

El cardenal Orazio Lancellotti, prefecto de la Sagrada Congregación de los Ritos ${ }^{50}$, encargó la traducción de los textos portugueses de 1556-1557 al latín, que fue realizada por el notario Juan Visetus, concluida el 11 de septiembre de 1612 y cotejada y aprobada por Nuño de Ares, comisionado del cardenal (24 de septiembre de 1612) $)^{51}$. A principios del mismo mes la Congregación de los Ritos había decidido iniciar los procesos apostólicos o remisoriales en las diócesis donde había vivido Javier y envió letras remisoriales para designar en cada una de ellas jueces remisoriales o subdelegados, facultándoles a su vez para delegar en otros jueces (como hizo el juez de Cochín en favor de los jueces de Tuticorín y Coulam ${ }^{52}$ ). En ellas se incluía también el interrogatorio del Santo Oficio ${ }^{53}$, que en el caso de Javier incluyó 61 preguntas, para examinar a los testigos e indagar sobre la «vida, virtudes y milagros» del siervo de Dios. A su vez, el P. Claudio Aquaviva, quinto prepósito general de la Compañía de Jesús (1581-1615), nombró como postuladores ante los diversos tribunales a los rectores de los correspondientes colegios (octubre de 1613) ${ }^{54}$. En 1616 el cardenal Francesco Bourbon del Monte sucedió a Lancellotti como prefecto de la Congregación de los Ritos, hasta su muerte en 1627, y dirigió la etapa más importante de la causa.

48 1567-1623. Lugarteniente de un auditor de las causas del Palacio Apostólico, fue nombrado arzobispo en 1612 y cardenal en 1621.

49 1574-1655. Nuncio en Nápoles (1621-1625) y en España (1625-1630), fue creado cardenal en 1630. Elegido papa con el nombre de Inocencio X (1644-1655).

50 Roma 1571-1620. En el consistorio del 17 de agosto de 1611, el papa Pablo V lo creó cardenal presbítero con el título de San Salvatore en Lauro. Ocupó los cargos de prefecto de la Sagrada Congregación de los Ritos (1611-1616) y luego de la Sagrada Congregación del Concilio (1616-1620).

51 Romana seu Indiarum canonizationis Serui Dei Patris Francisci Xaverii. Interpretatationes procesuum Indicorum, Goanus, Cochinensis, Bazainensis et Malacensis productorum, die XI septembris 1612 (MX, I, pp. 221, 268, 371).

52 MX, II, p. 530, 579.

53 José Manuel Marchal MarTíNeZ, Trento y... procesos de canonización, pp. 186-187.

54 Pamplona E (MX, II, pp. 644, 650, 658, 660, 669, 674). 
Desde 1580 Portugal y su imperio estaban ensamblados en la corona de España. Cuando a principios del siglo XVII se realizaron los procesos remisoriales en las Indias Orientales, estos territorios eran regidos por Felipe III, que había solicitado la beatificación del jesuita navarro. Cumpliendo las instrucciones pontificias, se realizaron nueve procesos remisoriales, cinco en las Indias Orientales y cuatro en Europa. Los cinco primeros han tenido una suerte diversa. El segundo proceso de Goa (1615), que contó con 56 testigos y se extendió a Damao y Thana ${ }^{55}$, no ha sido publicado y, fuera de Schurhammer, que lo consultó y utilizó, es difícil encontrar menciones a él. En el otro extremo geográfico, el segundo proceso de Malaca (1616) se ha perdido y sólo se conoce a través del resumen que el $\mathrm{P}$. Barradas hizo de él ${ }^{56}$. Ambos pudieron redactarse originariamente en portugués, como también lo fueron los tres restantes de Cochín (segundo) ${ }^{57}$, Tuticorin ${ }^{58}$ y Coulam-Travancor ${ }^{59}$, aunque se han conservado mediante la traducción latina efectuada en Roma en 1617: «Processus in India Orientali facti pro canonizatione Patris Francisci Xaverii annis 1616 et $1617 \gg^{60}$.

Cronológicamente, el primero de los procesos de la India Oriental fue el realizado en Cochín entre julio y septiembre de 1616, que era el segundo de los procesos efectuados en esta ciudad, que había sido un núcleo clave en la actividad misional de Javier, tanto como punto de irradiación hacia Travancor como escala en los viajes entre Goa y las restantes posesiones portuguesas de Asia. Tiempo antes de que comenzara el proceso apostólico, Cochín y su entorno geográfico veneraban al Padre Maestro Francisco como un santo, que contaba ya con varias imágenes en las iglesias de algunas localidades de la zona o próximas a ella, como Kottar, Manpulin y Rettura ${ }^{61}$. Los jesuitas del colegio de Cochín impulsaban este culto mediante la difusión entre sus alumnos de una medalla en cuyo anverso estaba la Virgen María con el Niño Jesús y en el reverso el Padre Maestro Francisco ${ }^{62}$. Eran situaciones que poco después Urbano VIII prohibió mediante los decretos de Non Cultu (1625 y 1631).

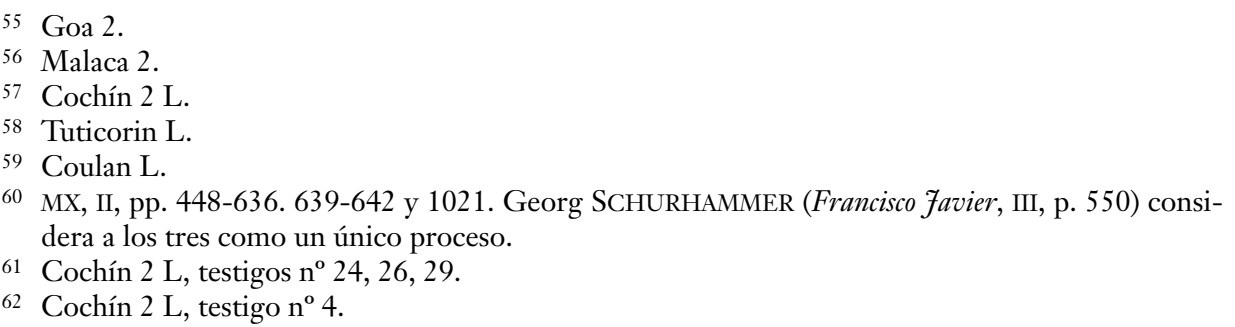


Esta situación dio lugar a un proceso extenso, en el que intervinieron 62 testigos, que representaban el caleidoscopio social de la colonia. Predominaban ampliamente los portugueses, que suponían tres cuartas partes de los testigos y se repartían por igual entre los nacidos en la metrópoli ${ }^{63}$ y en la India, hijos de portugueses asentados definitivamente en las colonias ${ }^{64}$. Continuaba la presencia de la baja nobleza y los funcionarios reales ${ }^{65}$, pero adquirían un peso similar los propietarios y comerciantes «more indiano» ${ }^{66}$, es decir, al por mayor. Un cambio significativo fue la presencia de dos frailes dominicos ${ }^{67}$, que depusieron en favor de la santidad de Javier, y, sobre todo, tres jesuitas, que también lo hicieron ${ }^{68} \mathrm{y}$ rompieron la regla no escrita de evitar la presencia de miembros de la Compañía de Jesús, que había presidido los procesos de 1556-1557 y trataba de evitar cualquier acusación de parcialidad. Con todo, la mayor novedad estribaba, con respecto a los procesos de 1556-1557, en la apertura a la realidad indígena mediante la presencia de 13 testigos: siete indios ${ }^{69}$, tres chinas $^{70}$, un moluqueño ${ }^{71}$, una malaya ${ }^{72}$ y un príncipe del reino de las Islas Maldivas ${ }^{73}$. La santidad de Javier se empezaba a percibir a través de los testimonios de los receptores de su actividad misionera.

El proceso de Cochín tiene dos partes diferenciadas. Primero se relacionan las declaraciones de 43 testigos $^{74}$. Entre ellas tuvieron especial relevancia siete testigos que rondaban o sobrepasaban ampliamente los 80 años y que, por lo tanto, habían conocido directamente al santo, tanto en Cochín como en Malaca. Además de ratificar de primera mano la fama de santidad («vir sanctus») y el celo misional de Javier, aportaron testimonios sobre hechos sorprendentes o sobrenaturales, que fueron tenidos en cuenta ${ }^{75}$. Los testigos que no llegaban a esa

63 Cochín 2 L, testigos n ${ }^{\circ} 10,14,17,20,21,22,23,26,63,33,34,37$.

64 Seis nacidos en Cochín, tres en Goa, uno en Meliapur (o Madrás) y uno en Malaca (Cochín 2 L, testigos $\mathrm{n}^{\circ} 5,11,12,15,16,25,27,28,30,32,35$.

65 Cochín $2 \mathrm{~L}$, testigos $\mathrm{n}^{\circ}$ 5, 9, 11, 12, 15, 16, 18, 22, 34, 35, 40, 41, 42.

66 Cochín 2 L, testigos no 7, 8, 10, 14, 17, 21, 23, 28, 30, 31, 32, 33, 37.

67 Cochín 2 L, testigos n ${ }^{\circ} 19,20$.

68 Cochín 2 L, testigos no 25, 26, 27. Uno nacido en la metrópoli (Mondego), otro en Meliapur (o Madrás) y otro en Malaca.

69 Cochín 2 L, testigos $\mathrm{n}^{\circ} 6,24,29,38,47,48,57$.

70 Cochín 2 L, testigos no 3 (la misma en 44), 4, 63.

71 Cochín $2 \mathrm{~L}$, testigo $\mathrm{n}^{\circ} 1$.

72 Cochín 2 L, testigo n ${ }^{\circ} 2$.

73 Cochín 2 L, testigo n ${ }^{\circ} 43$. Era mestizo. Su madre era portuguesa.

74 Cochín 2 L, testigos $n^{\circ} 1$ a 43.

75 Cochín 2 L, testigos $n^{\circ} 1,2,3,4,5,6,7,21,30$. En algún caso la percepción de santidad proviene de un testimonio tan sincero como humilde, el del barbero que le cortaba el pelo y la barba y tenía familiaridad («egisse cum eo familiariter») con el «vir sanctus» $\left(\mathrm{n}^{\circ} 6\right)$. 
edad, que eran la mayoría, aportaron testimonios de segunda mano (más o menos fiables en función de la fuente) o acreditaron la existencia de un sensus fidelium favorable a la canonización. La gran protagonista del proceso de Cochín fue Lucía Villanzam, una viuda nacida en China ${ }^{76}$, que junto a la malaya Juana de Mello ${ }^{77}$ había asistido a las predicaciones y catequesis de Javier en Malaca. Además, tenía una de las medallas que representaban a la Virgen María con el Niño y al Padre Maestro Francisco, con la que había obtenido abundantes curaciones invocando, exclusivamente, el nombre de Jesús y la intercesión de Javier («En el nombre de Jesús y del Padre Francisco Javier, que se te devuelva la salud»), y tocando a los enfermos con la medalla. Son veinte declaraciones ${ }^{78}$ que hablan de ocho curaciones, pero que se centran expresamente en tres de ellas, acreditadas por los protagonistas (María Díaz ${ }^{79}$, Gonzalo Rodríguez del Valle ${ }^{80}$ y Manuel Rodríguez Figueiredo ${ }^{81}$ ) y tres o incluso cuatro testigos que, en cada caso, las corroboran. Se prescindió de otras curaciones ${ }^{82}$. Aportaron los últimos milagros recogidos en la bula de canonización de 1623. Tanto la aceptación de estos hechos considerados milagrosos como la apertura a los testigos autóctonos permiten concluir que la aportación de este proceso remisorial o segundo de Cochín fue notable a la causa de la canonización.

76 Cochín 2 L, testigo no 4 y 44.

77 Cochín $2 \mathrm{~L}$, testigo $\mathrm{n}^{\circ} 2$.

78 Cochín $2 \mathrm{~L}$, testigos $\mathrm{n}^{\circ} 44$ a 63.

79 Cochín 2 L, testigos n ${ }^{\circ} 45$ (María Díaz, nacida en Cochín), 46, 48, 50, 51.

80 Cochín $2 \mathrm{~L}$, testigos $\mathrm{n}^{\circ} 58$ (Gonzalo Rodríguez del Valle) y 52, 56, 59 (cirujano que no pudo curarle)

81 Cochín 2 L, testigos no 60 (Manuel Rodríguez Figueiredo) y 54, 57, 61 (médico que no pudo curarle).

82 Se desechó la curación de Magdalena Collasa, nacida en Cochín, atestiguada por tres testigos (Cochín 2 L, testigos n ${ }^{\circ} 62$ y 48, 49 63). Otras cuatro curaciones (Cochín 2 L, testigos n ${ }^{\circ} 47,48$, 50,53 y 62) sólo fueron declaradas por un testigo y no fueron muy tenidas en cuenta. Entre ellas es preciso mencionar la de un Padre de la Compañía de Jesús que desde hacía tres meses estaba mudo y sordo. Lucía Villanzam le toco con la medalla los oídos, los ojos y la boca, haciendo en ellos la señal de la cruz, y recobró completamente la voz y el oído (testigo n ${ }^{\circ} 47$ ). La ocultación del nombre concreto de este sacerdote jesuita, que tenía gran confianza en la medalla en cuestión y en la actuación de Lucía Villanzam («quendam Patrem Societatis Iesu... qui maxime confidebat in Deo et in medaliae P. Francisci Xaverii»), contraria a la lógica del proceso, que se basaba en la máxima identificación de los testigos y protagonistas, parece estar dictada por una calculada prudencia del rector del colegio y procurador del proceso, para evitar que un jesuita pudiera ser reconvenido por aceptar la actuación de una mujer laica que, en ciertos ámbitos curiales y en el seno de un proceso contradictorio como era el de canonización, podía ser tachada de impropia o próxima a la brujería, cuestión que el texto de las veinte declaraciones trata de evitar a toda costa, recalcando que en todo momento Lucia Villanzam sólo se empleaba la medalla, agua y la invocación a Jesucristo y al Padre Maestro Francisco. 
El proceso de Tuticorín es el segundo de la India Oriental y tuvo lugar del 2 de agosto al 23 de septiembre de 1616. Debería llamarse, con más propiedad, «proceso de la costa de Pesquería», porque Francisco de Angelis, juez que lo dirigió en nombre del juez subdelegado Pedro Núñez, no se limitó a tomar declaraciones en esta ciudad, sino que recorrió otras cinco sedes que abarcaban todo el vicariato de la Pesquería que él gobernaba: Manapar (actual Manapadd), Virandyanpatman, Punicale (actual Punnaikayal), Vembar y Manar, junto a Ceilán (Sri Lanka), deteniéndose especialmente en la primera y la última de las localidades ${ }^{83}$. Más allá del cambio de sedes, el proceso destaca por ser una aportación masiva de los «paravas», el pueblo predilecto de Javier en la India, al que pertenecen 25 de $\operatorname{los} 37$ testigos $^{84}$, que se proclaman «indus, natione parava» ${ }^{85}$. Sumados a otros siete testigos indios ${ }^{86}$, representaban una abrumadora mayoría india (más del $86 \%$ ), que reducía los testigos portugueses a sólo cinco $^{87}$. Incluso los cuatro clérigos que declaraban como testigos, también el juez, eran indios ${ }^{88}$. Vuelven a estar ausentes los jesuitas; incluso el procurador es un franciscano, el P. Francisco Cordeiro. Pero enseguida resuenan los ecos de las estructuras misionales creadas por Javier en la Pesquería a través de cuatro catequistas («canacapulas») y sacristanes o encargados de las iglesias en ausencia de sacerdotes ${ }^{89}$. Seguían presentes los funcionarios («patangatinos» o regidores municipales, jueces, escribanos, maestros...) pero estaban en minoría ${ }^{90}$. Como no podía ser menos, comparecieron los pescadores y comerciantes de perlas («piscator margaritarum») $)^{91}$, que eran la principal riqueza de la costa y que daban lugar a una activa vida económica, que resuena en un mayoritario grupo de comerciantes ${ }^{92}$ y propietarios $^{93}$, a los que se

83 En Manapar testificaron 14 personas, mientras que en Manar lo hicieron 12. Muy por detrás se sitúan Virandyanpatman (4), Punicale (2), Vembar (1) y Tuticorín (4).

84 En la edición de MX, para numerarles, se continúa la numeración de los testigos de Cochín, del $\mathrm{n}^{\mathrm{o}} 64$ al 100, que sigo para facilitar la consulta.

85 Tuticorin L, testigos $\mathrm{n}^{\mathrm{o}} 64$ a 76,78 a 81,83 a $87,89,95$ y 98.

86 Tuticorin L, testigos $\mathrm{n}^{\circ} 77,82,88,90,93,97,99$.

87 Tuticorín L, testigos $n^{\circ} 91,92,94,96,100$.

88 El juez había nacido en Santo Tomás de Meliapur, actual Madrás (o Chennai) (Tuticorin L, testigo $\mathrm{n}^{\mathbf{0}}$ 88). Los vicarios de Cabo Comorín y Manar eran paravas ( ${ }^{\circ} 89$ y 95$)$, como probablemente también lo era el beneficiado de Punicale, aunque sólo se proclama indio $\left(\mathrm{n}^{\mathrm{o}} 82\right)$.

89 Tuticorín L, testigos $\mathrm{n}^{\circ} 64,68,78,81$.

90 Tuticorín L, testigos $\mathrm{n}^{\circ} 65,70$ a 72, 76, 80, 91, 92, 94, 96, 100.

91 Tuticorín L, testigos $n^{\circ} 64,67,83$.

92 Tuticorín L, testigos $\mathrm{n}^{\circ}$ 66, 69, 71 a 75, 79, 80, 90, 99, 100.

93 Tuticorín L, testigos $\mathrm{n}^{\circ} 80,85$ a 87, 93, 97, 98 . 
debe añadir un cambista de moneda ${ }^{94}$, hasta representar entre los tres casi dos tercios de los testigos.

Eran pocos los testigos del proceso de Tuticorín que rondaban los 80 años y habían conocido personalmente a Javier, apenas tres ${ }^{95}$, que dieron cuenta del don de profecía ${ }^{96}$ que le asistía o de milagros señalados como la resurrección del niño caído en el pozo de Kombuturé o la del cabo Comorín ${ }^{97}$ y el don de lenguas ${ }^{98}$. Sin embargo, fueron abundantes los testigos que aportaron las noticias de testigos presenciales ya fallecidos, pero que eran cercanos para ellos, como sus padres ${ }^{99}$ o personas conocidas, a las que nombran con precisión suficiente como para dotar de credibilidad a sus testimonios ${ }^{100}$. Además, es frecuente que varios testigos presenciales o indirectos hagan referencia a los mismos hechos extraordinarios o milagrosos, abarcando a más de la mitad de los reconocidos por tales en la bula de canonización: don de lenguas ${ }^{101}$, rechazo de los badagas ${ }^{102}$, las resurrecciones de Kombuturé ${ }^{103}$, cabo Comorín ${ }^{104}$ o Mutani ${ }^{105}$, curación de las llagas de un mendigo ${ }^{106}$, curación de un ciego en Japón ${ }^{107}$, recuperación del bote del barco ${ }^{108}$, anuncio en Malaca de la victoria sobre los achines ${ }^{109}$, cuerpo incorrupto ${ }^{110}$; y ya después de su muerte, devolución de la vista a un ciego ${ }^{111}$, resurrección de un niño ${ }^{112}$ o concesión de hijos

94 Tuticorín L, no 77. Gonzalo Méndez, nacido en la península de Salssete (o Salcete) de Goa y bautizado en la parroquia de San Miguel Arcángel, era de casta brahmán («natione bracamana») y residía en Manapar.

95 Un cuarto octogenario confiesa que no lo conoció personalmente (Tuticorin L, testigo $\mathrm{n}^{\circ}$ 93).

96 Tuticorín L, testigo $\mathrm{n}^{\mathbf{0}} 71$.

97 Testimonio de Diego Fernández (Tuticorín L, testigo nº 98).

98 Tuticorín L, testigo $\mathrm{n}^{\circ} 79$.

99 Tuticorín L, testigos no $64,81,83,85,88,91$.

100 Agustín de Pina (Tuticorín L, testigos $\left.n^{\circ} 70,71,81\right)$, Paulo Vaz ( $\left.{ }^{\circ} 78\right)$, Pedro Fernández $\left(n^{\circ} 80\right.$, 84), Antonio Cheruquil ( ${ }^{\circ}$ 82, 83, 85, 87)

101 Tuticorín, testigos $n^{\circ} 77,85$.

102 Tuticorín, testigos $\mathrm{n}^{\circ} 94,95,97$.

103 Tuticorín L, testigos $\mathrm{n}^{\mathrm{o}} 78,80,82,83,85,87,90,98,99$.

104 Tuticorín L, testigos $\mathrm{n}^{\circ} 94,98$.

105 Tuticorín L, $\mathrm{n}^{\circ} 84,91,96$.

106 Tuticorín L, testigos $n^{\circ} 70,71,81,82,85,90$.

107 Tuticorín L, testigos n ${ }^{\circ} 92$.

108 Tuticorín L, testigos $n^{\circ} 92,96,98$.

109 Tuticorín L, testigos n ${ }^{\circ} 91,96,98$.

110 Tuticorín L, testigos no 94, 97, 98, 99, 100.

111 Tuticorín L, testigos $n^{\circ} 89,93$.

112 Tuticorín L, testigos $n^{\circ} 73,74,75$. 
por las oraciones ante la imagen de Kottar ${ }^{113}$, que entonces dependía del reino de Coulam, pero que formaba parte de la Pesquería, como sanciona la actual división administrativa india. También se veneraba otra imagen de Javier en Manapar ${ }^{114}$. El culto a ambas imágenes corrobora la extensión del sensus fidelium de los paravas, que le reconocían y proclamaban casi unánimemente como «hombre santo» ${ }^{115}$.

La aportación de los paravas para que fueran tenidos en cuenta los milagros que requería la canonización fue, por testimonios directos o indirectos, muy significativa. A la vez, los testimonios dejan constancia de que a principios del siglo XVII los paravas de la Pesquería seguían considerando a Javier como el «Padre santo», que les había librado de la opresión de los badagas, había arriesgado su vida por ellos e incluso les había defendido frente a los portugueses. Una veneración y un agradecimiento que hoy subsiste ${ }^{116}$.

El tercero de los procesos de la India Oriental, denominado proceso de Coulam y la región de Travancor, en el extremo meridional de la costa occidental de la India, tuvo como juez subdelegado al vicario de esta ciudad, Juan Rodríguez, y actuó como procurador de la Compañía de Jesús el P. Pedro Mexia, rector del colegio del Salvador. Tiene dos partes diferenciadas y se desarrolló en cuatro sedes. La primera parte tuvo lugar en Coulam, donde prestaron declaración 22 testigos entre el 6 de septiembre y el 15 de octubre de 1616 («Informatio facta Coulani»). La segunda parte, que reunió 16 declaraciones, se desarrolló en tres localidades de la región de Travancor («Informatio facta in ora Travancoris»): la fortaleza de Rettura («Rectora») ${ }^{117}$ (27 de octubre) y dos localidades situadas cer-

113 Tuticorín L, testigos $n^{\circ} 65,66,75,76,89,98$.

114 Tuticorín L, testigo $\mathrm{n}^{\circ} 76$.

115 Tuticorín L, testigos no 65 a 67, 71 a 77, 81, 82, 84, 86, 87, 89 a 91, 93, 94, 96, 98 a 100.

116 Como acredita, a modo de ejemplo, este hecho: «En 1992 se celebró un Congreso Nacional Javeriano para conmemorar los 450 años de la llegada de Javier a la India. Teólogos, sociólogos, historiadores presentaron la figura de Javier: describieron sus éxitos y subrayaron sus deficiencias. Al final del Congreso pidió la palabra una persona cuyo nombre no aparecía en el programa: una señora de edad madura, de físico pequeño y apariencia frágil; se presentó como Sra. Josephine Dias, decana del Departamento de Literatura Inglesa de la Universidad de Trichinopoli [Bharathidasan University, Tiruchirapalli, estado de Tamil Nadu, India] y dijo lo siguiente: "Yo soy parava, descendiente de aquellos parias descastados, pescadores de perlas, convertidos por San Francisco Javier. Vosotros los 'expertos' podéis daros el lujo de hablar de las 'deficiencias' de Javier en su labor misionera. Para nosotros, los paravas, Javier es algo diferente, no es un 'objeto' de estudio; Javier es para nosotros nuestro Padre en la Fe, Javier es el Apóstol que nos trajo la Fe en Jesucristo, el tesoro más grande de nuestras vidas"» (Manuel DÍAZ GáRRIZ, Favier vive, en Gujerat. Misioneros jesuitas en la India, 652 [2002], pp. 4-5).

117 Distaba de Kottar 20 leguas portuguesas (Cochín 2 L, testigo no 29), unos 110 km. 
ca del cabo Comorín ${ }^{118}$, Kottar en el interior ( 5 de noviembre) y Manakkudi en la costa (10 de noviembre) ${ }^{119}$. Las declaraciones se copiaron primero en borradores y el texto del proceso fue redactado definitivamente en Manakkudi entre el $10 \mathrm{y}$ el 16 de noviembre de $1616^{120}$.

El origen y la extracción social de los testigos de este proceso se aproximan a los de Tuticorin, pero sin llegar a su rotundidad de sus cifras. Los portugueses vuelven a ser minoría, menos de un tercio, y se concentran sobre todo en Cou$\operatorname{lam}^{121}$, mientras que casi dos tercios de los testigos son indios, malabares ${ }^{122} \mathrm{y}$, en el cabo Comorín, de nuevo paravas ${ }^{123}$. Sólo uno era chino ${ }^{124}$. Profesionalmente hablando, ocurre algo similar. Los funcionarios son un tercio, encabezados por el gobernador de Coulam y con notable presencia de jueces y escribanos, además de regidores locales ${ }^{125}$. Más abundantes entre portugueses, las declaraciones de jueces y escribanos permiten atribuir un marchamo de veracidad al conjunto del documento. Dos tercios de los testigos son propietarios y comerciantes, con predominio de los mercaderes al por mayor («more índico») ${ }^{126}$ sobre los dueños de comercios urbanos que vendían al por menor («more oppidano») ${ }^{127}$. Hay también

118 Esta zona del cabo Comorín donde se encuentran Kottar y Manukkudi pertenecía entonces al reino de Coulam, pero desde 1956 el distrito de Kanyakumari, de mayoría parava o tamil, no forma parte del estado de Kerala, sino de Tamil Nadu junto con toda la Pesquería.

${ }^{119}$ En la copia que maneja la edición de MX la separación entre las dos partes se colocó erróneamente entre los testigos $\mathrm{n}^{\circ} 106$ y 107 , debiendo en realidad situarse entre los $\mathrm{n}^{\circ} 122$ y 123 a tenor de las datas tópicas que acompañan a las fechas de las declaraciones. Como en el proceso de Tuticorim, se sigue la numeración de los testigos de MX, del n ${ }^{\circ} 101$ al 138.

${ }^{120} \mathrm{El}$ proceso fue cerrado el 16 de noviembre por el juez subdelegado y el notario Francisco de Motta con sus firmas, pero a continuación se añadió la declaración $\mathrm{n}^{\circ} 138$, hecha el 5 de noviembre, que, al redactar el texto final del proceso, no había sido copiada en el lugar que le correspondía junto a las de Kottar ( ${ }^{\circ} 128$ y 129). La primera exclusión de este testigo y su posterior inclusión pudo deberse al hecho de ser pagano («Testis ethnicus examinatus in hac causa»). Este detalle evidencia, desde la perspectiva de la génesis diplomática, la separación entre la actio (recogida de declaraciones en borrador desde el 6 de septiembre o, si sólo fue para la segunda parte desde el 27 de octubre, hasta el 10 de noviembre), y la conscriptio (ordenación y redacción final del texto, del 10 al 16 de noviembre en Manakkudi).

${ }^{121}$ Coulam L, testigos $\mathrm{n}^{\circ} 101$ a 103, 105, 109 a 112, 115, 116, 119. Solo uno de ellos había nacido en Portugal y tres son mestizos, de madre india $\left(\mathrm{n}^{\circ} 102,109,112\right)$.

122 Coulam L, testigos $\mathrm{n}^{\circ} 104,107,108,114,120$ a 127.

${ }^{123}$ Coulma L, testigos $n^{\circ} 128$ a 138. Además, parecen paravas tres indios más $\left(n^{\circ} 113,117,118\right)$

124 Coulam L, testigo $\mathrm{n}^{\circ} 106$.

125 Coulam L, testigos $\mathrm{n}^{\circ} 101$ (gobernador de la fortaleza), 102, 103, 109, 110, 116, 126, 132 (jueces), 105,111 (escribanos) y 123, 125 (regidores).

126 Coulam L, testigos $\mathrm{n}^{\circ}$ 104, 107, 108, 110 a 112, 116, 118 a 120, 128. Probablemente también lo eran otros ( $\mathrm{n}^{\circ} 123$ a 125,133 a 137$)$.

127 Coulam L, testigos $\mathrm{n}^{\mathrm{o}} 114,127$. 
un pequeño grupo de artesanos (dos sastres, un pescador de perlas y un curtidor de pieles) ${ }^{128}$.

$\mathrm{Al}$ igual que en los procesos anteriores, todos los testigos de Coulam y Travancor reconocían en Javier un «vir sanctus», que merecía la veneración de toda la población cristiana y también de los paganos («ethnici») ${ }^{129}$, y le atribuían un celo por la salvación de las almas («zelantissimus salutis animarum») ${ }^{130}$ que le había llevado a desplegar una desbordante actividad misionera. Los malabares y paravas de Travancor veneraban no sólo al P. Francisco, sino también a sus imágenes ${ }^{131}$. Aunque la Compañía de Jesús no activó la beatificación de Javier hasta que logró la de san Ignacio (1609), con anterioridad había impulsado su culto público, especialmente en dos lugares. Uno era la iglesia de Kottar, cerca del cabo Comorín, edificada en 1603 por el P. Bucerio, a la que llegó desde Roma una imagen de Javier $^{132}$, que enseguida se hizo célebre por las gracias y milagros que se le atribuyeron, incluso en sus lámparas ${ }^{133}$. Los fieles, y también los paganos, pedían gracias y hacían votos de realizar donaciones si las conseguían ${ }^{134}$. Había medallas de Javier, se celebraba su fiesta el día de su muerte (que entonces se creía el 2 de diciembre) y se componían canciones en su alabanza en lengua malabar ${ }^{135}$. El segundo lugar donde se rendía culto a Javier era en la capilla de san Ignacio del colegio de la Compañía en Coulam, que contó primero con un lienzo del misionero («depicta imago») y luego con la imagen traída de $\operatorname{Kottar}^{136}$. Medallas ${ }^{137}$ y reliquias ${ }^{138}$ alentaban la devoción a Javier.

Las declaraciones de los 38 testigos de Coulam y Travancor dejan constancia, como en los anteriores procesos, de las gracias y milagros atribuidos a la intercesión del futuro santo. Son muchos los hechos extraordinarios recogidos,

128 Coulam L, testigos $\mathrm{n}^{\circ} 113,117,130,138$.

${ }^{129}$ Coulam L, testigos $\mathrm{n}^{\circ} 107$ a 109, 114, 122, 129. El último testigo incluido en el proceso, llamado Pacna, era un pagano («natione ethnicus») de Kottar que trabajaba como curtidor de pieles $\left(n^{\circ} 138\right)$.

${ }_{130}$ Coulam L, testigo $\mathrm{n}^{\circ} 111$; «ubicumque est posita imago dicti Patris, habetur in magna veneratione et populus ei se commendat, et ad suas necessitates eius auxilium implorant» $\left(\mathrm{n}^{\circ} 103\right)$.

131 «universus hic populus ex ora Travancoris habent devotionem et venerationem erga dictum P. Franciscum, et etiam imágenes illius» (Coulam L, testigo $\mathrm{n}^{\circ} 114$ ).

132 Coulam L, testigos $\mathrm{n}^{\circ} 101$ a $105,114,114,116,123$ a $125,129$.

133 Coulam L, testigos $\mathrm{n}^{\circ} 101,102,105,107$ a $109,128$.

134 Coulam L, testigos $\mathrm{n}^{\circ} 108,114,132,133$ a $135,138$.

135 Coulam L, testigos n ${ }^{\circ} 104,106,107,113$.

136 Coulam L, testigos no $101,102,110,111,116$.

137 Coulam L, testigos n ${ }^{\circ} 110,111,120,122$.

138 Trozos de su túnica (Coulam L, testigos no 110,120 ). 
pero quizás los más importantes son sólo los pocos que, una vez cribados y depurados los testimonios, se incluyeron en la bula de canonización. En Kottar tuvieron lugar la resurrección de un niño de un mes de edad ${ }^{139}$, la recuperación de la visión por un ciego ${ }^{140}$ y la curación de un leproso con el aceite de la lámpara de la iglesia ${ }^{141}$. En la capilla de Coulam tuvo lugar la curación súbita y total de una joven de 17 años, Francisca Rebella, que padecía flujo sanguíneo ${ }^{142}$. Nuevos testimonios reforzaron otros milagros importantes recogidos en el proceso de Tuticorín ${ }^{143}$, donde ya se ha señalado la influencia de la iglesia de Kottar. Por testimonios directos o indirectos se recuerdan hechos sobrenaturales de la vida de Javier acaecidos en otros ámbitos geográficos, especialmente relacionados con sus viajes marítimos, como la conversión de agua salada en dulce ${ }^{144}$ y otros ${ }^{145}$, o la levitación al celebrar misa ${ }^{146}$. También se registran los dones y ayudas recibidas para lograr embarazos o resolver partos ${ }^{147}$.

Los tres procesos de la India Oriental sirvieron para afianzar y ampliar el amplio elenco de los milagros que sustentaron la canonización de san Francisco Javier y lo hicieron dando entrada en el proceso a los testimonios de las poblaciones indias, singularmente paravas y malabares, que habían sido las receptoras de su esfuerzo misionero y atestiguaban la misma veneración y fama de santidad que desde mediados del siglo XVI le atribuían los colonizadores portugueses que habían participado en los procesos de 1156-1557. La aportación de ambos grupos humanos, colonizadores y colonizados, era necesaria para tener una visión completa de la persona que se pretendía elevar a los altares, al menos en el ámbito de la India.

La pérdida del proceso de Malaca de 1616 impide corroborar o matizar esta visión desde el ámbito indonesio. Lo mismo puede decirse de Japón, ausente de nuevo de los procesos remisoriales de 1616-1617, porque desde 1587, cuatro años después de que el daimyo de Bungo pidiera la beatificación de Javier, To-

\footnotetext{
${ }^{139}$ Coulam L, testigo $\mathrm{n}^{\circ} 136$.

140 Coulam L, testigo $\mathrm{n}^{\circ} 107$.

141 Coulam, testigos $n^{\circ} 103,107$.

142 Atestiguada por ella misma y por su padre (Coulam L, testigos $\mathrm{n}^{\circ} 115$ y 109).

143 Coulam L, testigos no 96 y 129; 98 y 134; 107.

${ }^{144}$ Refrendada por un testigo presencial que declara en el proceso, el chino Joanes Boteglio, de 85 años (Coulam L, testigos $\left.\mathrm{n}^{\circ} 105,106\right)$.

145 Recuperación del esquife de la nave y sus tripulantes, perdidos en una tempestad al volver del Japón (Coulam L, testigo $\left.\mathrm{n}^{\circ} 106\right)$ o el milagro del cangrejo en las Molucas $\left(\mathrm{n}^{\mathrm{o}} 105\right)$.

146 Coulam L, testigos $\mathrm{n}^{\circ} 105,110,114$.

147 Coulam L, testigos $n^{\circ} 107,108,122$ a $124,130,131$.
} 
yotomi Hideyoshi había prohibido el cristianismo en el país y había ordenado la expulsión de los misioneros jesuitas. En 1597 fueron ejecutados los 26 mártires de Nagasaki, beatificados en 1627 y 1629, poco después de Javier. La persecución se reactivó en 1614 por orden del shogun Tokugawa Ieyasu y alcanzó su cumbre en 1637 , con la rebelión y martirio de miles de cristianos.

\section{ESCASA RELEVANCIA DE LOS PROCESOS EUROPEOS}

Además de los cinco procesos de las Indias Orientales, se han identificado cuatro procesos remisoriales realizados en Europa para contribuir a la beatificación y canonización de san Francisco Javier. El encargo de realizar procesos diocesanos afectó a tres ámbitos europeos en los que discurrió la trayectoria vital de Javier: España, Portugal y Roma. Nada se dice de París, quizás porque la renovación de los componentes de la universidad de la Sorbona hacía difícil la transmisión de noticias sobre un grupo de universitarios que, cuando abandonó París el 15 de noviembre de 1536, sólo dejaba un anclaje, Diego de Gouvea, Principal del Colegio de Santa Bárbara, que se mantuvo en el cargo hasta 1548 y que se trasladó a Lisboa en 1555. Sesenta años después era difícil encontrar testimonios, aunque fueran indirectos, sobre los once años que Javier había vivido en la universidad de la Sorbona.

Los procesos existentes son cinco: el de Pamplona, dos de Lisboa y dos de Roma. Su conocimiento y el acceso a su consulta es muy distinto, porque el de Pamplona ha sido publicado en los Monumenta Xaveriana, mientras que los de Lisboa y Roma pasan desapercibidos y sólo son citados de forma incidental por Schurhammer. Refiere que 22 personas declararon en el primer proceso de Roma (1610), de carácter general y que por su fecha no pudo ser un proceso remisorial, sino elaborado como inicio de la causa de canonización ${ }^{148}$. Utiliza el segundo proceso de Roma (1613), que fue un proceso remisorial particular o «in specie», con 7 testigos, para recoger una opinión de Simón Rodríguez, miembro del grupo fundador de la orden y enviado a Portugal junto con Javier, sobre la santidad del navarro ${ }^{149}$.

148 Georg SCHURHAMMER Francisco favier, III, p. 550. Lo usa, por ejemplo, para citar a un testigo de la profecía que Javier hizo a Francisco de Aguiar en 1551 sobre la larga vida que tendría tanto él como la carabela Santa Cruz (ibid., IV, p. 404).

149 Transmitida por el jesuita Nicolás de Almazán, testigo en el proceso de Roma de 1613, que coincidió con Simón Rodríguez en España entre 1569 y 1573 (Georg SCHURHAMMER, Francisco Favier, I, p. 952 y II, p. 892). 
El primer proceso de Lisboa (1614-1615), que contó con 23 testigos, le sirve para hablar de los compañeros jesuitas que quedaron en Portugal cuando Javier partió para la India ${ }^{150}$ y de dos profecías que el santo hizo al final de su vida ${ }^{151}$, así como su amistad con un piloto ${ }^{152}$. El segundo proceso de Lisboa (1616), que contó con 22 testigos, tampoco le aporta grandes datos ${ }^{153}$. Esta escasa utilización de los cuatro procesos se puede deber a la irrelevancia que tuvieron en la causa de canonización. Sin saber la razón de su preterición en la causa, quizás hay que atribuirla a la participación en ellos de jesuitas como testigos, que no se da en los procesos remisoriales de las Indias Orientales (salvo en el de Cochín) y que pudo aconsejar un uso reducido de los procesos de Lisboa y Roma en la causa, para evitar cualquier atisbo o acusación de parcialidad o falta de objetividad en sus testimonios. Si así fue, se trató de una medida prudente, que reforzó la fuerza probatoria de la causa de canonización.

La escasa relevancia del proceso de Pamplona (1614) se puede intuir por la existencia de la versión original en castellano y la ausencia de una traducción al latín, la lengua de la curia romana en la que se tramitó toda la causa. Sin embargo, su preterición no se debe a la presencia de jesuitas, ni tampoco a la de familiares directos del santo que pudieran ser tachados de partidistas. La selección de los testigos fue cuidadosa para evitar estos inconvenientes, a pesar de que existían descendientes directos de tres hermanos (Miguel, Juan y Ana) del siervo de Dios, entre los que destacaba Juan de Garro, señor de Javier y vizconde de Zolina, bisnieto de Miguel. Además, es preciso tener en cuenta que la familia vivió con indiferencia o con oposición la adhesión de Javier a la Compañía de Jesús, porque desbarató las expectativas sociales que el linaje esperaba de sus estudios en la universidad de París. A su vez, en 1540 Francisco no pasó por

150 Entre ellos estaba un joven italiano de 22 años, Bernardino Excalceato, que acabó entrando en la Compañía con el nombre de Bernardino dos Reis y murió en Lisboa en 1575. Transmitió su impresión sobre la santidad de Javier a un testigo del proceso de Lisboa, el jesuita Fernando Guerreiro, historiador de la Compañía «Patrem Xaverium ab eo deductum in navim, quando in Indiam velam fecit, et magnam sibi cum illo intercessisse familiaritatem, et varia ipsi testi narrasse de sanctitate dicti Patris, cuius rei ipse testis non bene recordabatur» (fol. 50r-50v) (Georg SCHURHAMMER, Francisco favier, I, p. 935; III, p. 550).

${ }^{151}$ Las profecías sobre Francisco de Aguiar y la carabela Santa Cruz (1551) y sobre Pedro Velho (1552) (Georg SCHURHAMMER, Francisco Favier, III. p. 550; IV, p. 404, 406, 799).

152 Gonzalo Fernandez (1546), a quien antes había convertido en Goa (Georg SCHURHAMmER, Francisco favier, III, p. 73, 550).

${ }^{153}$ Lo cita incidentalmente para hablar de curaciones en Punicale (1544), uno de los muchos testigos del anuncio de la muerte de Joao de Araujo (1546) o de la ya citada profecía sobre Pedro Velho (1552) (Georg SCHURHAMMER, Francisco Favier, II, pp. 584, 965; III, p. 550; IV, p. 800). 
Pamplona, sino por Loyola, cuando iba camino de Portugal. Sólo hay algunos gestos de aproximación por parte de su hermano Juan al final de su vida, en la década de 1550, y las relaciones quizás se restablecieron en torno a 1568, cuando un nieto de su hermana Ana ingresó en la Compañía de Jesús ${ }^{154}$. Su hermano Miguel murió en 1542 y hasta 1561 el gobierno del castillo de Javier lo ejerció su viuda Isabel de Goñi; no hay noticias de que Miguel o Ana mantuvieran relaciones con Francisco o con la Compañía de Jesús. La carta autógrafa del santo dirigida a Juan de Azpilicueta (1535) fue entregada por éste a su cuñada Isabel de Goñi en 1555; sus descendientes la donaron al rector del colegio de Pamplona, fundado en 1580, y los jesuitas la depositaron en 1595 en el colegio de Alcalá155. En un inventario del castillo de 1605 nada se dice de documentos relacionados con el gran misionero ${ }^{156}$, cuya santificación se intuía próxima. Cuando se celebró el proceso de Pamplona (1614), también había desaparecido del castillo la carta que Magdalena de Jaso, hermana del santo, había dirigió a Miguel en 1533, para que no dejara de pagar los estudios de Francisco en París, misiva que no dejaba en buen lugar a Miguel. Poco podían aportar los descendientes directos a la causa de canonización.

Sólo se han conservado 19 folios del proceso de Pamplona y alguno de ellos tiene el número 146, lo que hace pensar que se ha conservado, aproximadamente, un $10 \%$ del mismo. Corresponden a las declaraciones de siete de los 15 testigos $^{157}$. Como Francisco salió de Navarra en 1525, son testigos de segunda o tercera mano, parientes lejanos o personas que transmiten lo que han oído a otras personas. Ya en 1931 se señalaba su escaso interés para aportar noticias sobre las virtudes, milagros y actividad misionera de san Francisco Javier, limitándolo a

154 Plasmé algunas razones de estas afirmaciones hace dos décadas en un texto (Favier y Navarra: contexto bistórico-familiar), que sólo vio la luz de forma evanescente por vía digital, hoy extinta. Espero retomar la cuestión. Baste decir que hacia 1552 Juan de Azpilcueta, hermano de Javier, puso el nombre de Francisco a su único y tardío hijo varón, pero cuando murió en 1556 no encargó ninguna de las 500 misas en sufragio de su alma a los jesuitas, sino a cinco conventos y parroquias de Navarra. En 1568 un nieto de su hermana Ana, Jerónimo de Ezpeleta, entró en la Compañía de Jesús y acabó siendo un gran misionero en el imperio mogol de la India, donde utilizó el nombre de Jerónimo de Javier. En 1545 había entrado en la Compañía un primo tercero de Francisco, Juan de Azpilcueta, pero lo hizo desde Portugal, donde vivía con su tío Martín de Azpilcueta, muy lejos de la familia inmediata de San Francisco Javier.

155 Georg SCHURHAMMER, y Joseph WIKI, Epistolae Sancti Francisci Xaverii aliaque eius scripta ( $\ll$ Monumenta Historica Societatis Iesu», vol. 67), I, Roma, 1944, p. 1.

156 Publicado por Georg SCHURHAMMER, Inbentario de los vienes que quedaron en Xavierr, en Príncipe de Viana, 11/40-41 (1950), pp. 309-328.

157 Joaquín María GoIBURU, San Francisco favier, patrono de las misiones, Madrid, 1952, p. 111: Georg SCHURHAMMER, Francisco Favier, III, p. 550. 
algunas noticias curiosas de su familia en Navarra ${ }^{158}$. Con todo, el testimonio del vicario de la parroquia de Javier permite comprobar la extensión de la devoción al futuro santo en su solar en 1614, incluso entre extranjeros y gentes venidas de las Indias, que se acercaban al castillo para venerar sus recuerdos ${ }^{159}$.

Todos los procesos que se han comentado sirvieron para que desde 1610 a 1618 los tres auditores de la Rota Romana, Francesco Sacrati, Giovanni Battista Cocçini y Giovanni Battista Pamphilii, tramitaran la causa de canonización de san Francisco Javier. Sus trabajos y decisiones están recogidas en las correspondientes Actas $^{160}$. El resultado de su trabajo fue un Summarium ${ }^{161}$, que resumía la causa, y la Relatio $^{162}$, ricamente encuadernada, en la que recomendaban al papa Paulo V la beatificación y canonización del misionero navarro.

158 Así lo hizo Francisco Escalada, al reeditarlo parcialmente (Documentos históricos del castillo de favier y sus mayorazgos, Madrid, 1931, p. 292-302, en concreto p. 293). Sólo se han conservado las declaraciones de siete testigos. Dos son parientes muy lejanos, Miguel de Eguía (nieto de un primo segundo del santo) y Martín de Azpilcueta (hijo de un primo cuarto del santo, pero cuya abuela María de Garínoain, 1496-1584, con la que había convivido 19 años, sí que pudo conocer y tratar a Francisco Javier antes de partir de Navarra en 1525). Quizás entre las partes perdidas del proceso pudieron declarar como testigos familiares más cercanos. Tuvo cercanía con los señores de Javier el testigo fr. Benito de Ozta, prior del vecino monasterio de Leire, y el vicario de Javier. No se puede decir lo mismo de los tres restantes testigos, uno de ellos abogado de los tribunales reales, otro canónigo de la catedral de Pamplona y el tercero sin definir profesionalmente.

${ }^{159}$ Fermín Cruzat y Sabalza, vicario de la parroquia de Javier, nacido en la vecina localidad de Yesa en 1576, había convivido 18 años con su abuelo Juan Miguel, 1504-1594, «que conocio muy bien al P. Francisco Xauier», aunque no aporta noticias interesantes por ello. Destaca más bien por dejar constancia del paso por Javier de abundantes devotos: «Y por veneraçion y deboçion del dicho siervo de Dios, dibersas gentes vienen a aquella cassa y castillo a visitalle, y particularmente al aposento, en donde por comun tradiçion esta obseruado que naçio el dicho Padre Xauier, assi seculares como religiosos, de dibersas naçiones, y algunos de las Indias, que han llevado pedaços de ladrillos, y llevando estillas de las puertas del dicho aposento, y besando la tierra y paredes del mismo» (MX, II, p. 677).

160 Actas de las sesiones de los tres auditores de la Rota, Roma, 1610-1618 (ROMA, BIBLIOTECA INNOCEnZIana, Codex 468, hoy en el Archivo Doria Pamphilii); Georg Schurhammer, Francisco favier, III, p. XXXIV.

161 Summarium Romana seu Indiarum Canonizacionis Servi Dei Beati Patris Francisci XAVERII, [1618], (BIBLIOTECA VATICANA, Ottoboni latina 467, f. 735r-978v); Georg SCHURHAMMER, Francisco favier, II, p. XXXII; III, p. XXXIV.

162 Relatio Francisci Sacrati Archiepiscopi Damasceni, Iohannis Baptistae Coccini, Decani, Iohannis Baptistae Pamphilii, Rotae auditorum, facta Sanctissimo Domino Nostro Paulo Papae V super sanctitate et miraculis Patris Francisci Xaverii Societatis Iesu ex processibus super illius canonizatione formatis extracta, [Romae, 1619], (BIBLIOTECA VATICANA, Barberini Latina 2772); Georg SCHURHAMMER, Francisco Favier, II, p. XXIX; III, p. XXXI. 


\section{REFERENCIAS BIBLIOGRÁFICAS}

Apostle of the Indies. Bull canonizing St. Francis Xavier, en Lux in arcana. The Vatican Secret Archives reveals itself, Roma, 2012.

Astrain, Antonio, Historia de la Compañia de Jesús en su asistencia de España, I, Madrid, 19021925,7 vols.

Barradas, Manuel, Rellaçam de algumas coisas notaveis de N. Santo Padre Francisco Xavier, tiradas dos procesos autenticos, que por orden da Santidade do Papa Paolo quinto se tirarao nesta Cidade de Cochim, e na de Malaca, nas fortalezas de Coulao e Manar, e nas Costas de Pescaria e Travancor, en Georg SCHURHAMmER, Gesammelte Studien, IV, pp. 436-465.

DÍAZ GÁRRIZ, Manuel, Favier vive, en Gujerat. Misioneros jesuitas en la India, 652 (2002), pp. 4-5.

ESCALADA, Francisco, Documentos históricos del castillo de favier y sus mayorazgos, Madrid, 1931, pp. 292-302.

FORTÚN PÉREZ DE CIRIZA, Luis Javier, Realidad política e ideal religioso en la vida de San Francisco favier, en Ignacio ARELlano (coord.), Sol, Apóstol, Peregrino. San Francisco Zavier en su Centenario, Gobierno de Navarra, Pamplona, 2005, pp. 80-91.

GoIBURU, Joaquín María, San Francisco favier, patrono de las misiones, Madrid, 1952.

Marchal Martínez, José Manuel, Trento y la redefinición del Catolicismo. Los procesos de canonización, en Memoria honrosa de un Caballero. Estudios en el V Centenario del Caballero de Gracia, Real Oratorio del Caballero de Gracia, Madrid, 2017, pp. 179-190.

Monumenta Xaveriana ex autographis vel ex antiquioribus exempli collecta ( $\ll$ Monumenta Historica Societatis Iesu», 16 y 43), 2 vols., Madrid, 1899-1912.

PAPA, Giovanni, Le cause di canonizzazione nel primo periodo della Congregazione dei Riti: (15881634), Urbaniana University Press, Roma, 2001.

SÁ, Artur Basilio DE, Documentação para a história das Missões do Padroado Português do Oriente, Lisboa, 1954-1958, 5 vols.

SCHURHAMmer, Georg, Francisco favier, 4 vols., Gobierno de Navarra, Pamplona, 1992.

- Inbentario de los vienes que quedaron en Xavierr, en Príncipe de Viana, 11/40-41 (1950), pp. 309-328.

- Die Lissabonner Heiligsprechungsprozesse Franz Xavers, en Gesammelte Studien, IV, RomaLisboa, 1965, pp. 419-429.

- Uma relacao inédita do P. Manuel Barradas SI sobre Sao Francisco Xavier, en Gesammelte Studien, IV, pp. 431-436.

SCHURHAMmER, Georg y WIKI, Joseph, Epistolae Sancti Francisci Xaverii aliaque eius scripta («Monumenta Historica Societatis Iesu», vols. 67 y 68), Roma, 1944-1945, 2 vol. 


\section{Anexo \\ RELACIÓN DE PROCESOS}

\section{PRIMER PROCESO DE GOA}

1556, noviembre 18 / diciembre 9 y 1557, agosto 3-18, Goa.

«Averiguación que se hizo de la vida y trabajos del Padre Maestro Francisco, de la Compañía de Jesús, que en estas partes pasó, y también de las cosas de edificación y sobrenaturales que en vida de dicho Padre y después de ella Nuestro Señor obró por medio de él», hecha por Ambrosio Ribeiro, provisor y vicario general de la diócesis de la India, por mandato del rey Juan III de Portugal en carta dirigida desde Lisboa (28 de marzo de 1556) al virrey de la India, Francisco Barreto.

Goa $1 \mathrm{P}$ - Versión primera en lengua portuguesa.

«Inquiriçao que se tirou da uida e trabalhos que o Padre Maestre Francisco, da Companbya de Jesu, n'estas partes pasou, e asy das cousas de edificaçao e sobrenaturais que em vida do dito Padre e depois d'ella Nosso Senhor por ele obrou».

Escribano: P. Jorge Gómez, capellán de la catedral de Goa.

El texto actual es una segunda copia notarial. Ambrosio Ribeiro autorizó la primera copia del proceso, que fue adverada también por Gonzalo Lorenzo de Carvalho, canciller real, y Francisco Álvarez, oidor general (10 enero 1557). Cuatro días después (14 enero 1557) de la copia anterior se hizo la segunda copia por mandato de Francisco Álvarez oidor general y juez de apelaciones, a petición del rector y padres (jesuitas) del colegio de san Pablo de Goa, realizada por su escribano general Andrés Rodríguez, firmada también por otro escribano, Ayres Vaz, y sellada con el sello real grande.

MX, II, pp. 173-219 y 1020.

Goa $1 \mathrm{~L}$ - Traducción en lengua latina de la segunda versión portuguesa.

«Inquisitio factae Goae de vita et moribus Patris Franciscii Xaverii Societatis Iesv praesertim uero de laboribus quos ille in India pro Christi amore et animarum salute pertulit, deque egregiis ipsius factis, et potissimum de miraculis, quae Deus per ipsum, et ante et post eius obitum, edidit».

Fue ordenada, a partir de la segunda versión portuguesa del proceso (1557), por el cardenal Orazio Lancellotti, prefecto de la Sagrada Congregación de los Ritos. Realizó la traducción el notario Juan Visetus y se terminó 11 septiembre 1612; fue cotejada con el texto portugués y aprobada por Nuño de Ares, comisionado del cardenal (24 septiembre 1612).

$$
\text { MX, II, pp. 221-268 y } 1021 .
$$




\section{PRIMER PROCESO DE MALACA}

1556, noviembre 24 y 1557, mayo 18-19. Malaca.

Averiguación de Malaca, hecho en virtud de la orden del rey Juan III y de la provisión extendida por Francisco Barreto, gobernador de la India, para que se diera cumplimiento a la orden real. Fue realizada por Juan Pereira, capitán de la ciudad de Malaca, con la colaboración de Diego de Andrade, oidor de la ciudad, a requerimiento del P. Baltasar Díaz, de la Compañía de Jesús.

Malaca $1 \mathrm{P}$ - Versión primera en lengua portuguesa.

Incluye copia de la real cédula de Juan III (28 marzo 1556) y la provisión real extendida por el gobernador (10 septiembre 1556). Actuó como escribano Diego Fernández.

El texto editado es una segunda copia notarial. La primera fue extendida en Malaca (18 octubre 1557) por el mismo redactor del original, el escribano Diego Fernández, sellada con el sello real de la ciudad. Cotejada por el oficial real Roque de Oliveira y por el escribano, está suscrita también por el capitán Juan Pereira. La segunda es una de las tres copias otorgadas en Cochín (8 de enero de 1558) por mandato del licenciado Antonio Leytao, oidor real en Cochín, y cotejadas por el oficial Manuel de Araujo, hechas a petición de los Padres de la Compañía de Jesús para mandarlas por tres vías diferentes, mientras se quedaban con la primera copia notarial.

MX, II, pp. 413-419 y 1021.

Malaca $1 \mathrm{~L}$ - Traducción en lengua latina.

Realizada en 1612, sigue el texto portugués.

Roma, ARSI.

MX, II, pp. 431-447 y 1021 .

\section{PRIMER PROCESO DE BASAÍN}

1556, diciembre 10. Basaín (actualmente Vasai-Virar).

«Averiguación de la vida y honestidad del Padre Maestre Francisco, hecha por Simón Travasos, vicario de esta ciudad de Baçaim, por mandato del Rey Nuestro Señor».

Basaín $1 \mathrm{P}$ - Versión primera en lengua portuguesa.

«Baçaim. Incrisao da vyda e onestidade do Padre Mestre Francisquo, tirada per mamdado d'el Rey Noso Senhor per Simao Trauasos, viguairo d'esta cidade de Baçaym».

Por orden del vicario actuó como escribano el beneficiado P. Francisco de Carvalho. 
Es texto editado es una copia notarial realizada en Goa por el escribano Diego Froes, sacada del original enviado desde Basaín, por orden de Antonio Ramgel de Castello Bramquo, vicario general y provisor del obispado de la India (24 de noviembre de 1557). Fue adverada también por Andrés Rodríguez, escribano de la auditoría general. A petición del rector y padres de la Compañía de Jesús (en Goa) fue certificada por el licenciado Enrique Jaques, oidor general de la India designado por el rey de Portugal.

MX, II, pp. 371-388 y 1020.

Basaín 1 L - Traducción en lengua latina.

«Inquisitio de vita et moribus Patris Franciscii Xaverii, facta a Simone Trauasos, Bazaini, Cambajae urbis, vicario, ex mandato regis Lusitani».

Realizada en 1612, sigue el texto portugués.

MX, II, pp. 394-408 y 1021.

\section{SEGUNDO PROCESO DE BASAÍN}

1557, enero 6. Basaín (actualmente Vasai-Virar).

Averiguación hecha por una provisión real, extendida a nombre de Juan III, a petición de los padres de la Compañía de Jesús y realizada por el licenciado Enrique Jaques, oidor general de la India.

Basaín $2 \mathrm{P}$ - Versión primera en lengua portuguesa.

«Baçaim».

Actuó como escribano Lope de Aguiar.

El texto editado es la primera de tres copias notariales realizadas en Goa (15 de diciembre de 1557) por Manuel Varela, escribano de la auditoría general, cotejada por el licenciado Gonzalo Lorenzo de Carvalho, juez, y por el licenciado Enrique Jaques, oidor general, que dan fe de ello con sus respectivas firmas.

MX, II, pp. 388-394 y 1020.

Basaín 2 L - Traducción en lengua latina.

Realizada en 1612, sigue el texto portugués.

MX, II, pp. 408-412 y 1021.

\section{PRIMER PROCESO DE COCHÍN}

1557, enero 8. Cochín

«Averiguación que se hizo de la vida y trabajos del Padre Maestro Francisco en estas partes de la India», hecha por el P. Pedro González, vicario de Cochín 
y capellán real, por orden del virrey o gobernador Francisco Barreto, dada desde Pamgym (4 noviembre 1556), que se inserta, a petición de los Padres de la Compañía de Jesús.

Cochín $1 \mathrm{P}$ - Versión primera en lengua portuguesa.

«Imquirao que se tirou da vida e trebalhos do Padre Mestre Francisco n'estas partes da Imdia».

Actuó como notario el sacerdote P. Francisco Fernández, que conservó el original del proceso.

El texto editado es una copia notarial redactada por el escribano Gómez Suárez en Cochín 19 días después de la expedición del original (27 enero 1557), hecha a petición del P. Pedro González y certificada por Antonio Leytao, oidor real en Cochín, con las diligencias firmadas por ambos.

MX, II, pp. 268-322 y 1020-1021.

Cochín $1 \mathrm{~L}$ - Traducción en lengua latina.

«Cochinensis. Inquisitio de vita et laboribus Patris Magistri Francisci in his Indiae partibus facta».

Realizada en 1612, sigue el texto portugués.

MX, II, pp. 322-371 y 1021.

\section{PRIMER PROCESO DE ROMA}

1610. Roma.

Proceso general de Roma.

[Roma 1 L] - Probablemente el original se redactó en latín.

«Processus Romanus in genere».

Se conoce su existencia a través de una cita del mismo en las «Actas de las sesiones de los tres Auditores, Sacratus, Coccinus y Pamphilius» (Roma, [Archivo Doria Pamphilii], Biblioteca Innocenziana, Codex 468).

Georg SCHURHAMmer, Francisco Favier, III, p. 550; IV, p. 404.

\section{SEGUNDO PROCESO DE ROMA}

1613, Roma.

Proceso remisorial particular de Roma.

Roma 2 L - Redactado en latín. «Procesus Romanus in specie». 
[Roma 2 L] - Probablemente el original se redactó en latín.

Se conoce su existencia a través de una cita del mismo en las «Actas de las sesiones de los tres Auditores, Sacratus, Coccinus y Pamphilius» (Roma, [Archivo Doria Pamphilii], Biblioteca Innocenziana, Codex 468).

Georg SCHURHAMmer, Francisco favier, I, p. 952; III, p. 550.

\section{PROCESO DE PAMPLONA}

1614, febrero 25 / marzo 14. Pamplona.

Proceso remisorial diocesano de Pamplona, llevado a cabo por Prudencio de Sandoval, obispo de Pamplona, y Tomás Cortés, obispo de Jaca, jueces apostólicos subdelegados por los auditores romanos, a instancias del procurador P. Juan de Párraces, rector del colegio de la Compañía de Jesús en Pamplona.

Pamplona C - Texto en castellano.

Actúa como notario Alonso del Mazo.

Precede al texto título en latín («Processus Pampilonensis ad canonizationem B. P. Franciscii Xaverii. Fragmentum»), aunque el proceso está escrito íntegramente en castellano. Deponen siete testigos, pero es un fragmento de 19 folios, que suponen aproximadamente un $10 \%$ del texto, pues alguno de los folios lleva el número 146. La declaración de cada testigo está firmada por el testigo, los dos jueces y el notario.

El nombramiento de los jueces apostólicos subdelegados se había producido en Roma el día 6 de septiembre de 1613. La designación del P. Párreces como procurador de la Compañía de Jesús en el proceso tuvo lugar un mes más tarde, el 8 de octubre.

MX, II, pp. 643-679.

\section{PRIMER PROCESO DE LISBOA}

\section{4-1615. Lisboa}

Primer proceso remisorial de Lisboa.

Lisboa $1 \mathrm{~L}$ - Traducción en lengua Latina.

«Processus remissorialis Ulyssipona I».

Probablemente fue redactado en portugués, pero se conoce su existencia a través de su traducción latina, conservada en Roma, [Archivo Doria Pamphilii], Biblioteca Innocenziana, Codex 465.

Georg SCHURHAMMER, Die Lissabonner Heiligsprechungsprozesse Franz Xavers, en Gesammelte Studien, IV, pp. 419-429.

Georg SCHURHAMMER, Francisco Favier, I, p. 935; III, p. 73; IV, pp. 404, 406, 799. 


\section{SEGUNDO PROCESO DE GOA}

\section{Goa.}

Proceso remisorial de Goa.

Goa 2.

Incluye las declaraciones de 56 personas.

Georg SCHURHAMMER, Francisco Favier, III, 550-551; IV, p. 800.

\section{SEGUNDO PROCESO DE COCHÍN}

\section{6, julio 10 / septiembre 14. Cochín}

Proceso remisorial de Cochín, realizado por Pedro Núñez, deán, vicario capitular sede vacante y juez apostólico, en virtud de las letras remisorias presentadas por los jesuitas P. Andrés Macchiado, rector del colegio de la Compañía en Cochín, y el P. Francisco de Oliveira, procuradores sustitutos.

Cochín 2 L - Traducción en lengua latina.

«Processus Cocinensis», incluído en «Processus in India Orientali facti pro canonizatione Patris Francisci Xaverii annis 1616 et 1617».

Este proceso tiene dos partes. El texto propiamente dicho del proceso, que comprende los testigos $\mathrm{n}^{\circ} 1$ a 43 se elaboró entre el 10 de julio y el 25 de agosto de 1616 . La incorporación de un anexo, que conforma la segunda parte (testigos $\mathrm{n}^{\circ} 44$ a 63), se anuncia el 15 de julio en la declaración de Lucía de Villanzam (testigo ${ }^{\circ}$ 4), pero no tuvo lugar hasta el 10 de diciembre, cuando el P. Andrés Macchiado solicitó y obtuvo la incorporación de una copia notarial del proceso realizado en 1614 (septiembre 1 / octubre 10) en el palacio episcopal de Cochín por el juez Nicolás Cruz sobre los milagros realizados a través de una medalla de san Francisco Javier y gracias a las invocaciones de Lucía Vilanzam.

Los tres procesos de Cochín, Tuticorín y Coulam-Travancor, reunidos en «Processus in India Orientali facti pro canonizatione Patris Francisci Xaverii annis 1616 et 1617» se conservan en una de las tres copias solicitadas por el P. Andrés Machiado, rector del colegio de Cochín para ser enviadas a Roma, que fueron autorizadas por el licenciado Pedro Núñez, juez apostólico, y ejecutadas por el escribano Manuel Monteiro en cuatro cuadernillos de cinco pliegos (Cochín 10 de diciembre de 1616). Además de las firmas de los tres, la copia contaba con ocho sellos de seda rojos con la efigie de la (Inmaculada) Concepción, que usaba el juez Pedro Nuñez.

El texto original, escrito en portugués, fue traducido en Roma al latín por Antonio Díaz da Costa, licenciado en decretos, notario público apostólico, clérigo originario de la diócesis de Braga (30 septiembre 1617). La traducción latina fue cotejada con el original portugués por el notario Francisco Girardo, clérigo originario de la diócesis de Besançon, perteneciente al Franco Condado, en la actualidad territorio francés, pero entonces perteneciente al Sacro Imperio Romano Germánico y controlada por una guarnición española. 
La edición se realiza según el texto conservado en el códice «Processus orientales integri $\gg$ en Roma (ARSI, Postulador de la Compañía, n. 28. En ella se incluye, al final del proceso de Coulam-Travancor, el escatocolo, incluído el sello en cera roja del juez, pero que no se publica. Georg SCHURHAMMER (Francisco favier, III, p. 550) considera que este proceso y los dos siguientes constituyen un único proceso.

MX, pp. 448-530, 634-636 y 1021.

\section{PROCESO DE TUTICORÍN}

1616, agosto 2 / septiembre 23. Tuticorín (en la actualidad Thoothukudi). Proceso remisorial de Tuticorín, realizado por Francisco de Angelis, subdelegado del juez remisorial Pedro Núñez, y por el P. Francisco Cordeiro OFM, subdelegado del P. provincial franciscano de la provincia de Cochín.

Tuticorin L - Traducción en lengua latina.

«Processus inquisitionis testium, factus super vita, virtutibus ac miraculis Servi Dei Patris Franciscii Xaverii, religiosi Societatis Iesu. Tutuchurini», incluído en «Processus in India Orientali facti pro canonizatione Patris Francisci Xaverii annis 1616 et 1617».

V. información de Cochín $2 \mathrm{~L}$.

MX, II, pp. 531-578, 634-636 y 1021.

\section{Proceso de Coulam y TRaVANCor}

1616, septiembre 6 / noviembre 16. De Coulam (o Quilón, actualmente Kollam) a Manakkudi.

Proceso remisorial hecho en Coulam y en la región de Travancor por Juan Rodríguez, vicario de la iglesia de Coulam y juez subdelegado de Pedro Núñez, juez remisorial, a instancia del P. Pedro Mexía SI, rector del colegio del Salvador y procurador del P. Gaspar Fernández, provincial de la Compañía de Jesús.

Coulan L - Traducción en lengua latina.

«Processus testium depositionum interrogatorum Coulani et in ora Travancoris ad canonizationis servi Dei Patris Francisii Xaverii, per dominum foannem Rodriguez, vicarium generalem et judicem delegatum a reverendoi Patre Petro Nunez, decano, provisore, vicario generali et, sede vacante, praesside diócesis Coccinensis ac iudice apostólico delegato in bac causa», incluído en «Processus in India Orientali facti pro canonizatione Patris Francisci Xaverii annis 1616 et $1617 \gg$.

Actúa como notario Francisco de Motta.

V. información de Cochín $2 \mathrm{~L}$

MX, II, pp. 579-636 y 1021. 


\section{SEGUNDO PROCESO DE LISBOA}

1616. Lisboa.

Segundo proceso remisorial de Lisboa.

Lisboa $2 \mathrm{~L}$ - Traducción en lengua latina.

«Processus remissorialis Ulyssipona II».

Probablemente fue redactado en portugués, pero se conoce su existencia a través de su traducción latina, conservada en Roma (Archivo Doria Pamphilii), Biblioteca Innocenziana, Codex 466.

Georg SCHURHAMmer, Die Lissabonner Heiligsprechungsprozesse Franz Xavers, en Gesammelte Studien, IV, Roma-Lisboa, 1965, pp. 419-429.

Georg SCHURHAMMER, Francisco Favier, II, pp. 584, 965; III, pp. 550-551; IV, p. 800.

\section{SEgUNDO PROCESO DE MALACA}

\section{Malaca}

Como los restantes procesos remisoriales de este año, fue realizado por un juez subdelegado apostólico. Perdido en la actualidad, sólo se conoce el resumen que el P. Barradas hizo de él.

Manuel BarRaDAS, Rellaçam de algumas coisas notaveis de N. Santo Padre Francisco Xavier, tiradas dos procesos autenticos, que por orden da Santidade do Papa Paolo quinto se tirarao nesta Cidade de Cochim, e na de Malaca, nas fortalezas de Coulao e Manar, e nas Costas de Pescaria e Travancor, Lisboa, Biblioteca Ajuda, 49-6-9, f. 2-19; pub. en Georg SCHURHAMMER, Gesammelte Studien, IV, pp. 436-465.

Georg SCHURHAMMER, Uma relacao inédita do P. Manuel Barradas SI sobre Sao Francisco Xavier, en Gesammelte Studien, IV, pp. 431-436.

Georg SCHURHAMMER, Francisco Favier, III, p. 551; IV, pp. 664-665 y 725. 
